\title{
Nonlinear Pounding Analysis of Multispan and Simply Supported Beam Bridges Subjected to Strong Ground Motions
}

\author{
Hong-Yu Jia $\mathbb{D}^{\mathbb{D}},{ }^{1}$ Xian-Lin Lan $\left(\mathbb{D},{ }^{1}\right.$ Nan Luo $(\mathbb{D}),{ }^{1}$ Jian Yang, ${ }^{2}$ Shi-Xiong Zheng, \\ and Chao Zhang ${ }^{3}$ \\ ${ }^{1}$ School of Civil Engineering, Southwest Jiaotong University, Chengdu 610031, China \\ ${ }^{2}$ Guizhou Transportation Planning Survey \& Design Academe Co., Ltd., Gui Yang 550025, China \\ ${ }^{3}$ College of Civil Engineering of Fuzhou University, Fuzhou 350116, China
}

Correspondence should be addressed to Nan Luo; nanluo@swjtu.edu.cn

Received 9 May 2019; Accepted 29 May 2019; Published 7 August 2019

Academic Editor: Nicola Caterino

Copyright (c) 2019 Hong-Yu Jia et al. This is an open access article distributed under the Creative Commons Attribution License, which permits unrestricted use, distribution, and reproduction in any medium, provided the original work is properly cited.

To investigate the nonlinear impact effect of multispan simply supported beam bridges under strong earthquakes, firstly, the dynamic motion equation, the algorithm of its solution, and some pounding modelling methods are presented and the finite element model of a considered multispan simply supported railway beam bridge is established in the nonlinear finite element software of SAP2000 in which the primary nonlinear characteristics of the bearing and the impact element are considered herein. Secondly, the natural vibration characteristic of the considered railway bridge is analyzed to prepare for the subsequent parameter analysis. Finally, the influence of three nonlinear parameters, i.e., stiffness of impact element, separation gap width of expansion joint, and bearing stiffness, on impact responses of bridge structures is studied. The results show that the first several modes of multispan simply supported beam bridges are mainly longitudinal and vertical vibrations. Under longitudinal seismic excitations, the large longitudinal displacement response is induced possibly and results in the collision or even unseating of superstructures at the expansion joints and abutments. The influence of separation gap width between adjacent decks on the pounding effect of bridges is greater than that of collision stiffness originated from the pounding modelling element. The impact force and pounding number run up to the maximum conditional on the collision stiffness of $9.9 \times 10^{9}(\mathrm{~N} / \mathrm{m})$ and the separation gap width of $0.14(\mathrm{~m})$. The bearing stiffness affects significantly the displacement of the pier top and the cross-sectional internal force at the bottom of piers but has little effect on the collision force and number.

\section{Introduction}

Multispan simply supported beam bridge type is widely used in railway bridges on account of the advantages such as fast construction, standardized and assembled components, and convenient manufacture and installation. Moreover, the multiple span bridges are often built with the expansion joints to accommodate temperature- and number-dependent deformations. However, the expansion joints between two adjacent decks or between deck and abutment will be vulnerable components under strong ground motions, thanks to the superstructure pounding which may excite the local failure of deck itself and even catastrophic unseating damage.

Recently many earthquakes, e.g., Wenchuan earthquake (2008, M8.0) [1], Chile earthquake (2010, M8.8) [2], North
Sumatra earthquake (2012, M8.5), and Nepal earthquake (2015, M8.1) in the world occurred frequently whose magnitudes increased intensely as well. Meanwhile, these ground motions caused casualties, economic losses, and collision and collapse of structures including buildings and bridges. Hence, an increasing number of scholars all over the world have paid great attention to the collisions especially for the bridge pounding occurred between adjacent decks and between deck and abutment. Because of the complexity of the collision mechanism, it is extremely difficult to find an accurate fully collision simulation method. However, some practical and handy approaches are developed in recent studies [3-6]. For example, rooted in the law of conservation of energy and momentum, the collision process of building and bridge in earthquakes were simulated by using the 
method of restoring coefficient [7-10]. Among these scholars, Malhotra indicated the relationship among the restoring coefficient, the material damping ratio of the main girder, and the length ratio of the adjacent girders and considered that the duration of the collision is close to the basic period of axial vibration of relatively short segment in all of girders. The linear spring element was utilized to simulate the seismic impact of expansion joints of bridge structures [11]. The further improved element with the combination of spring and damper was used widely to consider the energy dissipation in the collision process. In general finite element software, e.g., Ansys, Abaqus, and Sap2000, this improved element was named as linear spring-damper element [12, 13]. For considering the nonlinear behavior in the pounding process, the nonlinear spring element was employed to model the nonlinear relationship between deformation and stress $[14,15]$. As known, the Hertz-damp model based on the nonlinear spring and damper element was developed to consider the energy dissipation, thanks to pounding better [16]. The threedimensional contact-friction model was adjusted to investigate the collision effect between adjacent bridge segments on the responses of bridge structures subjected to ground motions. However, due to the complexity of the contact algorithm this method failed widely to be applied in practical engineering for the investigation of pounding occurred between two adjacent bridge segments [17].

Not only are the methods of collision simulation studied but also the effects of the earthquake-induced pounding upon the entire and local responses of bridge structures. The isolation parameter analysis of a multispan simply supported beam bridge under spatial varying ground motions was conducted by Zanardo et al. [18] to explore the influence of seismic spatial variability on the impact of bridge segments, and the importance of isolation device installed between deck and pier was illustrated for reducing the bridge damages as a result of the earthquake-induced pounding. Based on random vibration theory, Hao [19] studied the influence of the damping, geological condition, and magnitude on the width demand of separation gap between two adjacent decks for pounding analysis of simply supported beam bridge under spatial ground motions. And it is expected that nonuniform vibration characteristics of two adjacent bridge segments are the predominant factors owing to asynchronous displacement responses excited by the spatially varying ground motions. On account of the simplified bilinear model, Ruangrassamee and Kawashima [20] proposed the relative displacement spectrum under collision conditions and believed that the pounding can result in the increase of demand width of expansion joints among adjacent segments. Jankowski et al. [21] and Ankowski et al. [22] presented the collision effect of single-column pier viaducts under ground motion excitations on the dynamical responses of structures and many mitigation measures are also introduced to reduce the damages induced by the pounding. Bi et al. [23] assessed the influence of spatial seismic nature, site condition, and pile-soil interaction on the demand of the designed separation gap length in the seismic analysis of bridge structures. Zhang et al. [24] and Jia et al. [25] proposed an efficient, accurate, and probabilistic analysis method for prediction and assessment of impact effects of high pier railway bridges subjected to three-dimensional nonstationary multisupport excitations. Won et al. [27] carried out the impact response analysis of multispan simply supported beam bridges under multisupport seismic excitations, but some detailed parameter analysis is insufficient such as stiffness and clearance of impact element. Liolios et al. [28] studied the impact effect of concrete beam bridges with the cable-limit devices fixed between two adjacent decks and expected that the impact was responsible for the bearing and unseating damages. Maragakis et al. [29] performed an elastic-plastic dynamical analysis of simply supported beam bridges for taking into account the impact effect between abutment and main girder. Moreover, the nonlinearity of the filled soil behind the considered abutments is considered for studying its influence on the responses of structures. Jankowski et al. [30] analyzed the collision effect occurred at expansion joints of multispan continuous girder bridges on the separation gap size to avoid the pounding.

Following the aforementioned reviews, the nonlinear pounding analysis of multispan simply supported beam railway bridges subjected to strong ground motions is studied rarely. In this study, the three-dimensional finite element model of a realistic multispan simply supported beam railway bridge is established based on SAP2000 platform. And the nonlinear properties of bearing and impact element are considered in the dynamical analysis of railway bridge structures. These considered nonlinearities include the width of expansion joint, impact stiffness, and longitudinal stiffness of bearing in the seismic analysis of employed realistic multispan simply supported beam railway bridges for providing in-depth insight into predicting or avoiding the collision damages of railway bridge structures.

\section{General Theory}

2.1. Dynamical Response Equation of Bridge Structures. The equation of motion of the lumped mass system subjected to ground motions can be formulated by expressing the equilibrium of the effective forces associated with each of its degrees of freedom. The force equilibrium of a multidegreeof-freedom lumped mass system as a function of number can be expressed by the following relationship:

$$
\mathbf{F}_{\mathrm{I}}(t)+\mathbf{F}_{\mathrm{D}}(t)+\mathbf{F}_{\mathrm{S}}(t)=\mathbf{F}(t)
$$

where $\mathbf{F}_{\mathrm{I}}(t)$ represents the inertial force vector acting on the node masses; $\mathbf{F}_{\mathrm{D}}(t)$ is a vector of viscous damping, or energy dissipation, forces; $\mathbf{F}_{\mathrm{S}}(t)$ denotes a vector of internal forces carried by the structure; and $\mathbf{F}(t)$ indicates a vector of externally applied forces.

For many structural systems, the approximation of linear structural behavior is made to convert the physical equilibrium statement to the following set of second-order, linear, differential equations as

$$
\mathbf{M} \ddot{u}_{\mathrm{s}}(t)+\mathbf{C} \dot{u}_{\mathrm{s}}(t)+\mathbf{K} u_{\mathrm{s}}(t)=\mathbf{F}(t)
$$

where $\mathbf{M}, \mathbf{C}$, and $\mathbf{K}$ represent the mass matrix, damping matrix, and stiffness matrix of structures, respectively. $\ddot{u}_{\mathrm{s}}(t)$, 
$\dot{u}_{\mathrm{s}}(t)$, and $u_{\mathrm{s}}(t)$ represent the absolute acceleration, absolute velocity, and absolute displacement of the structural system, respectively.

2.2. Hilber-Hughes-Taylor $\alpha$ Algorithm. Heretofore, the motion equation of the lumped mass system subjected to ground motions can be solved by several available methods, e.g., Newmark method, Wilson method, permutation method, Hilber-Hughes-Taylor (HHT) method, and Chung-Hulbert method. These methods have the same characteristics of implicit integration and unconditional stability. The Newmark method is the earliest method for dynamic solution, and some latter methods are modified or improved based on the Newmark method. It assumes the acceleration between arbitrary number intervals varies linearly in the dynamic analysis of structures. Thus, the iterative calculation is essential to the Newmark method which results in a significant amount of number to solve structural systems with just a few hundred degrees of freedom as a result of the large computational requirements.

In order to solve the above equations of motion, the improved Newmark method is used. This theory is briefly introduced below. Consider the solution of the linear dynamic equilibrium equations for one degree of freedom written in the following form [31]:

$$
M \ddot{u}_{t}+C \dot{u}_{t}+K u_{t}=F_{t} .
$$

The direct use of Taylor's series provides a rigorous approach to obtain the following two additional equations:

$$
\begin{aligned}
& u_{t}=u_{t-\Delta t}+\Delta t \dot{u}_{t-\Delta t}+\frac{\Delta t^{2}}{2} \ddot{u}_{t-\Delta t}+\frac{\Delta t^{3}}{6} \dddot{u}_{t-\Delta t}+\cdots \cdots, \\
& \dot{u}_{t}=\dot{u}_{t-\Delta t}+\Delta t \ddot{u}_{t-\Delta t}+\frac{\Delta t^{2}}{2} \dddot{u}_{t-\Delta t}+\cdots \cdots .
\end{aligned}
$$

Newmark truncated those equations and expressed them in the following form:

$$
\begin{aligned}
& u_{t}=u_{t-\Delta t}+\Delta t \dot{u}_{t-\Delta t}+\frac{\Delta t^{2}}{2} \ddot{u}_{t-\Delta t}+\beta \Delta t^{3} \ddot{u}_{t}, \\
& \dot{u}_{t}=\dot{u}_{t-\Delta t}+\Delta t \ddot{u}_{t-\Delta t}+\gamma \Delta t^{2} \ddot{u}_{t} .
\end{aligned}
$$

If the acceleration is assumed to be linear within the time step, the following equation can be written:

$$
\dddot{u}_{t}=\frac{\left(\ddot{u}_{t}-\ddot{u}_{t-\Delta t}\right)}{\Delta t} \text {. }
$$

The substitution of equation (7) into equations (5) and (6) produces Newmark's equations in standard form:

$$
\begin{aligned}
& u_{t}=u_{t-\Delta t}+\Delta t \dot{u}_{t-\Delta t}+\left(\frac{1}{2}-\beta\right) \Delta t^{2} \ddot{u}_{t-\Delta t}+\beta \Delta t^{2} \ddot{u}_{t}, \\
& \dot{u}_{t}=\dot{u}_{t-\Delta t}+(1-\gamma) \Delta t \ddot{u}_{t-\Delta t}+\gamma \Delta t \ddot{u}_{t} .
\end{aligned}
$$

The Newmark method is the earliest method for dynamic solution and some latter methods are modified or improved based on the Newmark method. It assumes the acceleration between arbitrary time intervals varies linearly in the dynamic analysis of structures. Thus, the iterative calculation is essential to the Newmark method which results in a significant amount of time to solve structural systems with just a few hundred degrees of freedom as a result of the large computational requirements.

For improving the computational efficiency and removing the numerical damping in high-order modes in structural analysis, Wilson introduces a coefficient $\theta$ to eliminate the fluctuation around real solution because of no unconditional stability in the Newmark method. Furthermore, HHT method is developed by introducing another coefficient $\alpha$ to modify the structural dynamic equation on the basis of the Newmark method. The modified dynamic equation is written as [31]

$$
\begin{aligned}
M \ddot{u}_{t}+(1+\alpha) C \dot{u}_{t}+(1+\alpha) K u_{t}= & (1+\alpha) F_{t}-\alpha F_{t} \\
& +\alpha C \dot{u}_{t-\Delta t}+\alpha K u_{t-\Delta t},
\end{aligned}
$$

where $\ddot{u}_{t}, \dot{u}_{t}$, and $u_{t}$ are the acceleration, velocity, and displacement at time " $t$," respectively; $\dot{u}_{t-\Delta t}$ and $u_{t-\Delta t}$ are the velocity and displacement at time " $t-\Delta_{t}$," respectively; and $\alpha$ is limited in the range of $[0,1 / 3]$. The method is equivalent to the average acceleration method when $\alpha=0$ in HHT. Thus, the HHT method is also called modified average acceleration method and is the most accurate in all of numerical methods. Nevertheless, the negative value of $\alpha$ is usually adopted to dissipate the high-frequency energy and better convergence.

\section{Pounding Theory}

Usually the bridge superstructure pounding occurs due to their out-of-phase movements once the relative displacement response of adjacent segments exceeds the separate distance (gap). As known, it is fairly difficult to model the pounding process based on the general finite element software platform due to its geometric and material complexity. Moreover, impact forces are applied and removed during a desperately short number, and the process of energy transfer is highly complicated [32]. Even though a precise simulation of pounding is difficult, various researches have been analytically studied based on two techniques. One is a stereo mechanical approach and the other is force-based approach. The stereo mechanical approach uses the principle of momentum conservation and the coefficient of restitution to modify the velocities of colliding structures after impact. The force-based approach utilizes contact elements consisting of a spring and a damper, which are extensively studied by many researchers. In brief, two main methods, the restoring coefficient method and the contact element method, for simulating the impact of bridge structures under earthquakes are presented herein.

3.1. Restoring Coefficient Method. Based on the assumption that the pounding is an impact occurred between two particle centers and is completed instantaneously, and the elastic-plastic impact is modelled by the restoring coefficient for the determination of velocity after pounding. In 
dynamical analysis of pounding according to the law of conservation of energy and momentum, the velocity of two particles after pounding can be obtained as

$$
\begin{aligned}
& \dot{v}_{1}=v_{1}-(1+e) \frac{m_{2}\left(v_{1}-v_{2}\right)}{m_{1}+m_{2}}, \\
& \dot{v}_{2}=v_{2}-(1+e) \frac{m_{1}\left(v_{1}-v_{2}\right)}{m_{1}+m_{2}},
\end{aligned}
$$

where $\dot{v}_{1}$ and $\dot{v}_{2}$ denote the separate velocity of two particles after pounding, respectively; $v_{1}$ and $v_{2}$ represent the velocity of two particles before collision; $m_{1}$ and $m_{2}$ represent the mass of two pounding particles, respectively; and $e$ is the restoring coefficient and decided by the following expression:

$$
e=\frac{\grave{v}_{2}-\dot{v}_{1}}{v_{1}-v_{2}}
$$

The different values of recovery coefficient represent different collision states; i.e., $e=0$ represents the complete elastic collision. Besides, Anagnostopoulos and Spiliopoulos [33] studied the collision problem of related structures under earthquakes by using the method of restoring coefficient and considered that the range of restoring coefficient is generally between 0.5 and 0.75 for solid collision of structures. Azevedo and Bento [34] suggested that the $e$ value of typical concrete structures should be 0.65 on the basis of relevant experimental results. The main girder collision of viaducts is investigated theoretically and experimentally, and an important conclusion is drawn that the value of $e$ should be reduced appropriately for the plasticity. Overall, the restoring coefficient method owns much many virtues, e.g., clear physical concept, simple algorithm, and understanding readily though it is based on the simplified impact model of two particles. But it cannot take into account the collision compression deformation of the contact areas and neglects the instantaneous stress and deformation in the collision phase. For bridge structures with larger mass and smaller elastic modulus, the impact deformation is larger and the duration is longer relative to other structures. It will be unreasonable to ignore the instantaneous stress and deformation in the impact stage. In addition, the restoring coefficient method is a dynamic collision simulation method and not yet force-based method.

3.2. Contact Element Method. Nowadays for the impact simulation of structures, the contact element method is an exceedingly fashionable algorithm embedded in general or professional finite element software such as Ansys, Abaqus, Sap2000, and Opensees. As regard to the contact element method, it is activated when superstructures of bridges are in contact and impact. Commonly, the contact element is composed of a spring with high stiffness to avoid material overlap and ensure short collision duration and a damper connected in parallel with the foregoing spring to simulate energy dissipation during collision. Generally contact elements include linear spring element, linear spring-damper element, nonlinear spring element, nonlinear springdamper element, improved nonlinear spring-damper element, and three-dimensional contact-friction element [35]. The linear spring element is the simplest in all, but it cannot consider the energy dissipation in the collision process so that the simulation accuracy and effect is also the worst. Three-dimensional contact-friction element can effectively simulate arbitrary collision between adjacent bridge segments and can also be implemented in numerical integration methods. However, it takes a lot of computing number to find contact pairs. Meanwhile, the calculation algorithm is quite complicated which restricts the development and application of this method to a certain extent.

In this study, the nonlinear gap-crush element from SAP2000 is utilized to simulate the impact of bridge superstructures [36]. This gap-crush element has following physical properties:

(1) Until the opening open gap is closed, the used element cannot develop a force. A negative value of open signifies an initial compression force.

(2) The element can only develop a negative compression force. The first yield deformation $d_{\mathrm{y}}$ is specified by a positive number.

(3) The crush deformation $d_{\mathrm{c}}$ is always a monotonically decreasing negative number.

The gap part of gap-crush element is set to study the collision among the adjacent decks of multispan simply supported beam bridges under earthquakes. The entire model is composed of a spring and an open gap in series. Its behavior is described as follows:

$$
\begin{aligned}
f_{t}^{(i)} & =k_{\mathrm{y}}\left(d_{t}^{(i)}+\text { open }\right)+\left(k_{\mathrm{e}}-k_{\mathrm{y}}\right) e_{t}^{(i)}, \\
e_{t}^{(i)} & =d_{t}^{(i)}+\text { open }-d_{\mathrm{c}}
\end{aligned}
$$

where $f_{t}^{(i)}$ is the iterative force, $k_{\mathrm{y}}$ is the yield stiffness, $k_{\mathrm{e}}$ is the initial linear stiffness, $e_{t}^{(i)}$ is the elastic deformation, $d_{t}^{(i)}$ is the compression deformation at number $t, d_{c}$ is the crush deformation at the end of collision, and open is the initial value for expansion joint.

\section{Bridge Model and Dynamic Characteristic Analysis}

4.1. Finite Element Model. For providing an in-depth insight into the pounding effect of multispan simply supported beam railway bridges under strong earthquakes a precast ballast-less track posttensioned prestressed concrete simply supported box girder (double track) railway bridge is employed in this study. As shown in Figure 1, this used railway bridge has span distribution of $6 \times 31.5(\mathrm{~m})$ and the width $12.6(\mathrm{~m})$ of the bridge deck. The box section is adopted in the main girder with variable section at the end support. In addition, the cross section of the rectangular solid pier is variable in the range of 3 meters below the bottom of the main beam and is equal in the range of 3 meters. The height of each pier is 14 meters. 


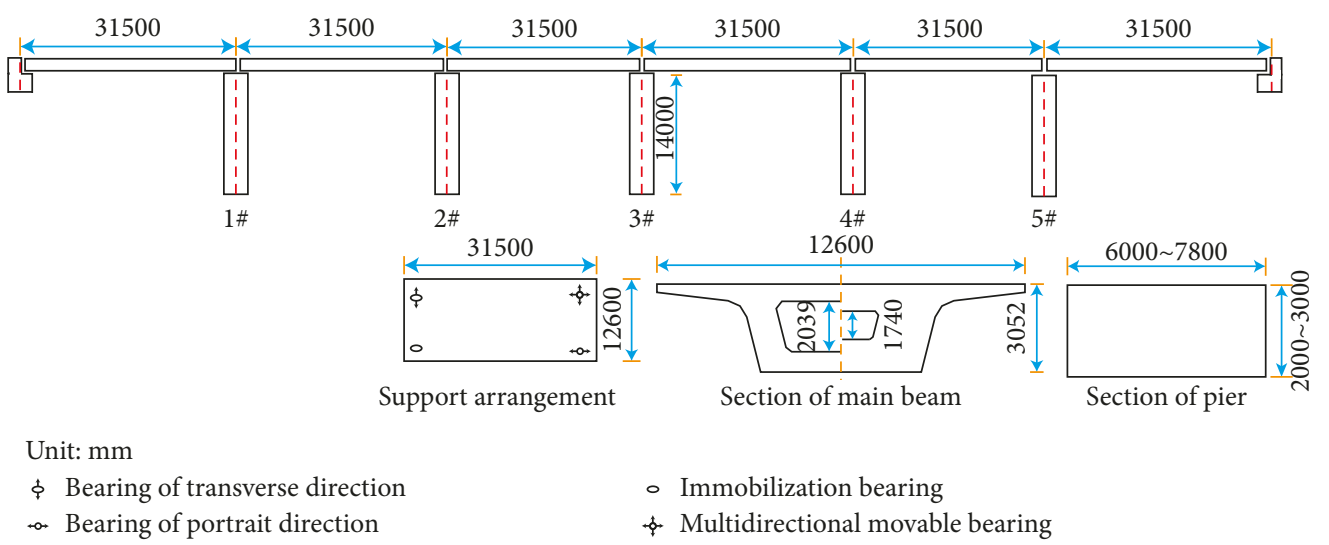

Figure 1: Schematic view of the railway bridge.

Each single span girder is supported by four basin rubber bearings, i.e., lateral movable bearing, longitudinal movable bearing, multidirectional movable bearing, and fixed bearing. The support arrangement of this railway bridge is shown in Figure 1. Moreover, the three-dimensional dynamic nonlinear analysis model of the multispan simply supported beam bridge is established by using the finite element software SAP2000, as shown in Figure 2. Both pier and girder are modelled by frame beam element, while the basin rubber bearings are modelled by using Wen plastic elements with nonlinear property. The restoring force model is given as follows:

$$
f=r \cdot k_{2} \cdot d+(1-r) \cdot \sigma_{y} \cdot z,
$$

where $k_{2}$ is the longitudinal stiffness of bearing, $\sigma_{\mathrm{y}}$ is the yield force, $r$ indicates the specified ratio of postyield stiffness to elastic stiffness, $z$ is the internal lag variable, and its restoring force model is also shown in Figure 2.

4.2. Dynamic Characteristic Analysis. Because the longitudinal dimension of the bridge is excessively larger than transverse one, the pounding of decks and even pull-offand-drop collapse are more likely to occur under the longitudinal seismic excitation. Therefore, this paper mainly studies the superstructure collision of bridges under the longitudinal seismic excitation. The natural vibration characteristics of bridges are the basis of dynamic analysis and has important role on the responses of structures. Due to the limited space, only the first six natural frequencies and modes are listed in Table 1. As seen in Table 1, the longitudinal vibration of both first two modes implies the potential pounding possibilities occurred in the longitudinal of the bridge.

\section{Numerical Analysis and Case}

5.1. Case. In order to study the nonlinear impact effect of multispan simply supported beam bridges under strong earthquakes, the artificial ground motion [37] is used as the excitation source in the nonlinear dynamic analysis. The open and impact stiffness values of gap/crush element are determined by a series of discrete values, namely, the open values are used, e.g., $0.1 \mathrm{~m}, 0.12 \mathrm{~m}, 0.14 \mathrm{~m}, 0.16 \mathrm{~m}$, and $0.18 \mathrm{~m}$, and the impact stiffness, i.e., $9.8 \times 10^{9}(\mathrm{~N} / \mathrm{m})$, $9.9 \times 10^{9}(\mathrm{~N} / \mathrm{m})$, and $1.0 \times 10^{10}(\mathrm{~N} / \mathrm{m})$, is ascertained in near the range of main girder stiffness [38]. Hence, totally 15 calculation cases are obtained according to the combination of open and impact stiffness.

\subsection{Parameter Analysis}

5.2.1. Force and Number of Collision. The pounding effect problem of bridges can be reflected by the collision contact force and number of pounding of bridges subjected to strong ground motions. For better pertinence, only the impact force and number of collision on the top of pier $1 \#$ will be discussed in detail. The relationship between the impact force and number of collision and the impact stiffness and open value is shown in Figures 3 and 4, respectively.

As seen in Figures 3 and 4, the overall trend of collision force varied consistently with different impact stiffness. The impact force increases firstly and then decreases drastically. The maximum collision force (about $9.62 \times 10^{7}(\mathrm{~N})$ ) occurs at the open value of $0.14 \mathrm{~m}$ and the collision stiffness of $9.9 \times 10^{9}(\mathrm{~N} / \mathrm{m})$. This performed analysis herein can derive the maximum impact force which may cause a serious damage to bridge structures under seismic excitations and provide a most critical design control point for engineers. From Figure 4, it reveals that the number of collision decreases with the increase of open value because adequate separation length between adjacent two decks can accommodate the relative displacement responses. When the open value changes from $0.10 \mathrm{~m}$ to $0.14 \mathrm{~m}$, the number of collisions decreases slowly. When the open value is greater than $0.14 \mathrm{~m}$, the number of collisions decreases significantly. It shows that the open value of $0.14 \mathrm{~m}$ is the change point. At the open value of $0.14 \mathrm{~m}$, the collision number at the impact stiffness of $9.9 \times 10^{9}(\mathrm{~N} / \mathrm{m})$ is 50 . Therefore, when the impact stiffness of the collision element is $9.9 \times 10^{9}(\mathrm{~N} / \mathrm{m})$ and the open value is $0.14 \mathrm{~m}$, it is the most disadvantageous condition. It should be noted that the reasonable separation gap width needs to ensure a smooth traffic flow. Namely, it is not that the longer the separation gap length is, the better the mitigating impact effect is. 


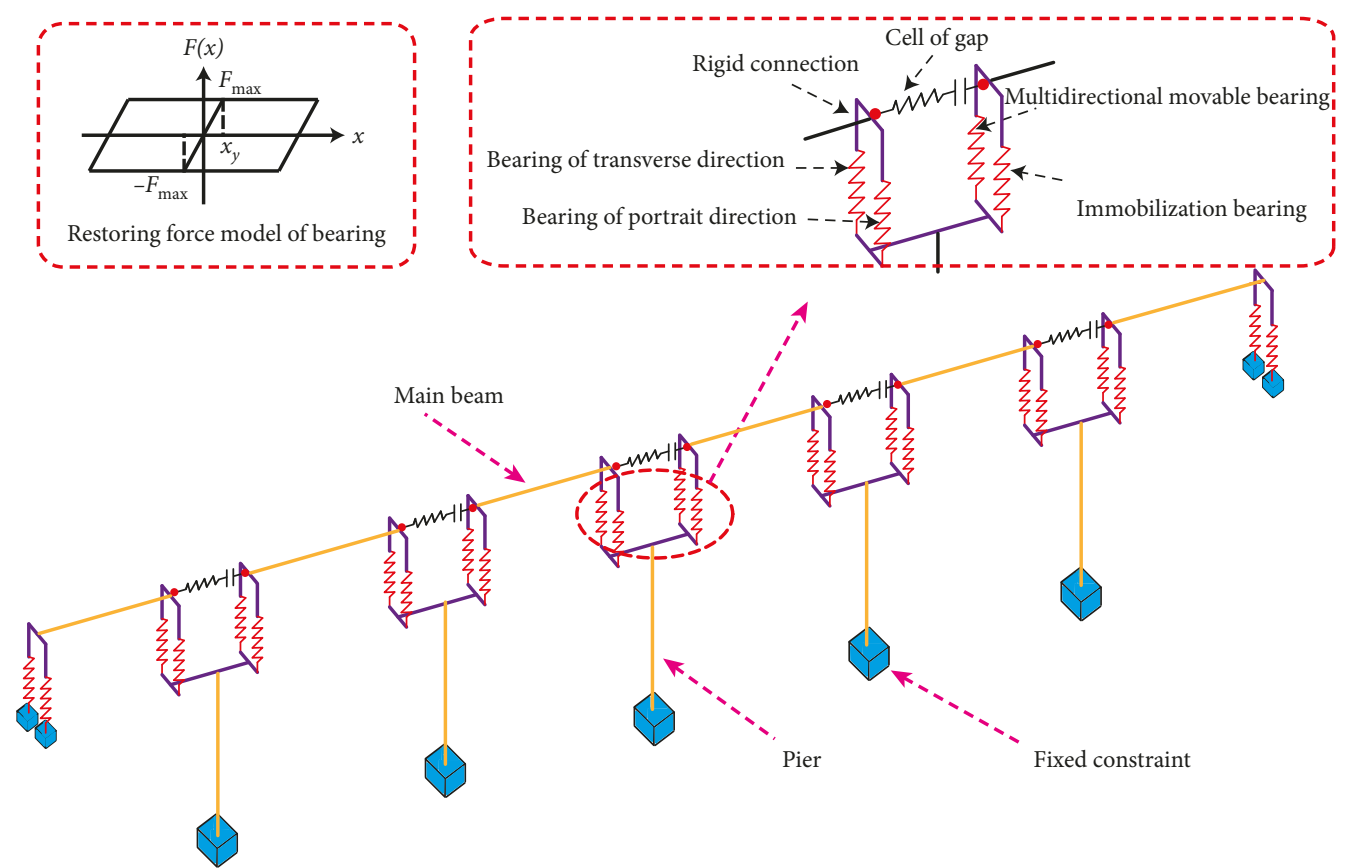

Figure 2: Finite element model.

TABLE 1: Natural frequencies and modes.

\begin{tabular}{lcc}
\hline Orders of modes & Frequency $(\mathrm{Hz})$ & Mode \\
\hline 1 & 3.598 & Antisymmetric longitudinal vibration \\
2 & 6.813 & Symmetric longitudinal vibration \\
3 & 7.849 & First-order antisymmetric vertical bending vibration \\
4 & 8.102 & First-order symmetric vertical bending vibration \\
5 & 8.933 & Second-order symmetric vertical bending vibration \\
6 & 10.524 & Second-order antisymmetric vertical bending \\
\hline
\end{tabular}

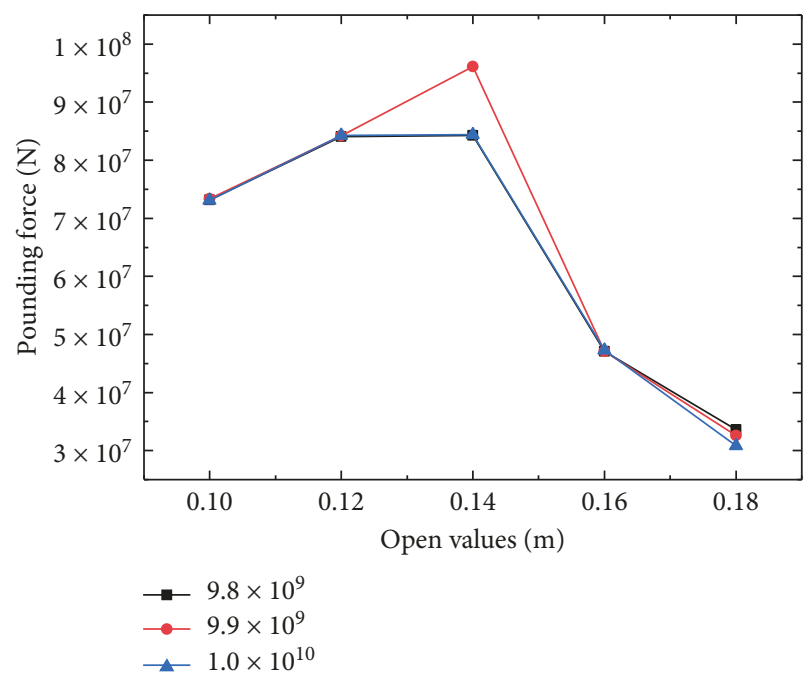

Figure 3: Collision force.

The time history of impact force in Figure 5 shows the pounding occurs mainly at three number intervals, i.e., 15-20 (s), 30-32 (s), and 37-41 (s). During each pounding

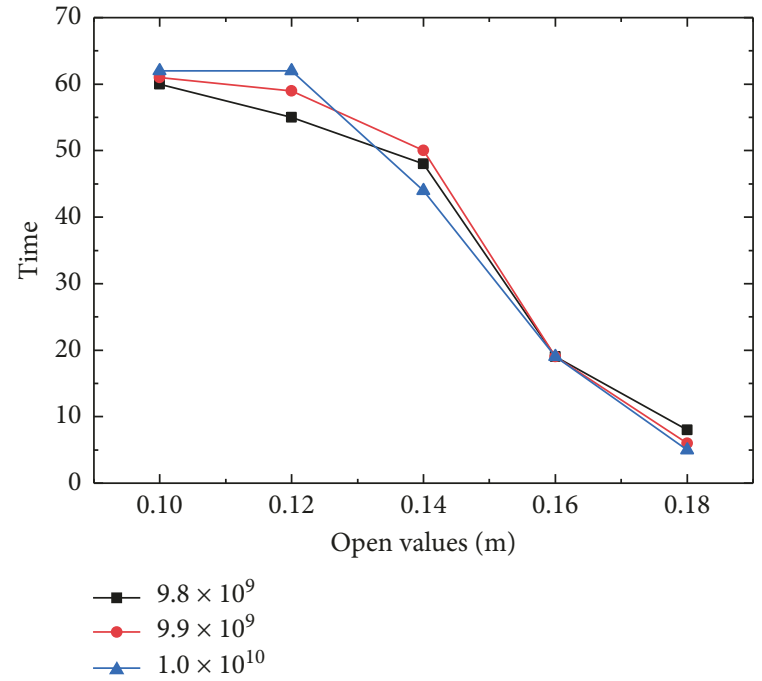

FIgURE 4: Number of collisions. number interval, the pounding force increases firstly and then reduces to zero lasting to the beginning of next collision. From Figure 6, it can be revealed that the pounding 


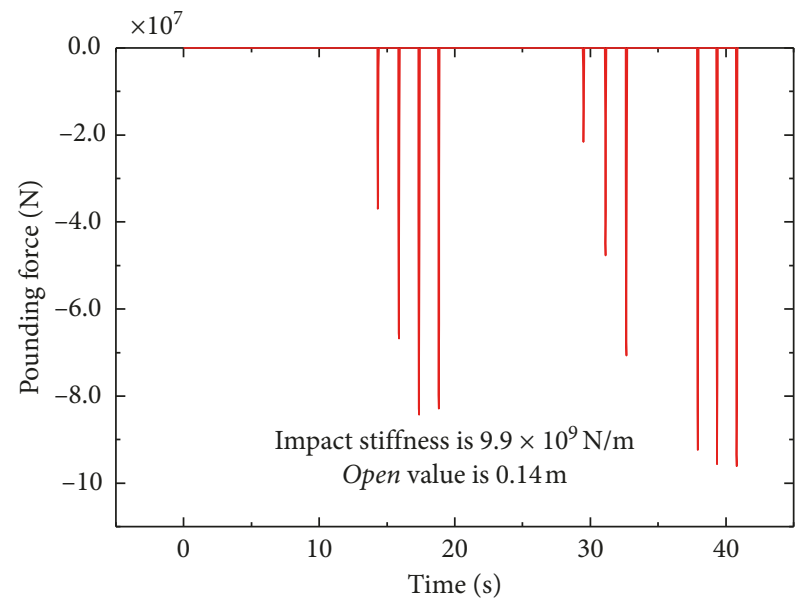

Figure 5: Time history of collision force.

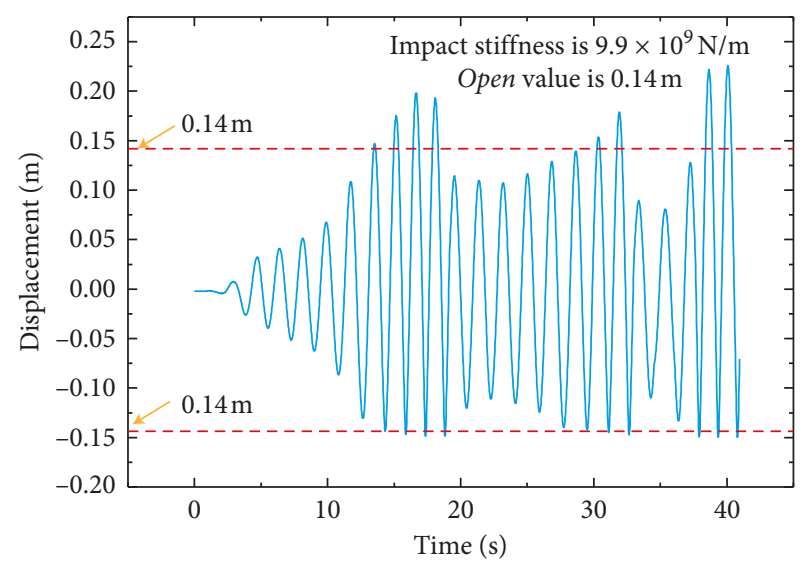

FIGURE 6: Longitudinal relative displacement response.

occurs once the longitudinal relative displacement response exceeds the open value of $0.14 \mathrm{~m}$ confirmed in impact element. Additionally, the impact number observed from longitudinal relative displacement response in Figure 6 is consistent completely with that obtained from impact force aspect in Figure 5.

5.2.2. Displacement Response. The impact parameters (stiffness and open value) are discussed only from the view point of impact element. The validity of the above conclusions is further verified from the angle of pier top displacement. The peak displacement on the top of pier $1 \#$ is shown in Table 2 . In the column of working conditions in Table 2, 0.1 of " $0.1-9.8$ " represents the open value of $0.1 \mathrm{~m}$, while 9.8 represents the impact stiffness of $9.8 \times 10^{9}(\mathrm{~N} / \mathrm{m})$ and so on.

From the overall analysis in Table 2, it can be seen that the displacement of pier top decreases with the increase of impact stiffness and open value. Under the same open value and different stiffness values, the peak displacement of the pier top of the same pier is approximately close. This indicates that the impact stiffness has little effect on the displacement responses. While under the same impact stiffness
TABle 2: Peak displacement (m).

\begin{tabular}{lccccc}
\hline Case & $1 \#$ & $2 \#$ & 3\# & 4\# & $5 \#$ \\
\hline $0.1-9.8$ & 0.4279 & 0.3906 & 0.3445 & 0.3931 & 0.4474 \\
$0.1-9.9$ & 0.4279 & 0.3906 & 0.3492 & 0.3931 & 0.4473 \\
$0.1-10$ & 0.4471 & 0.428 & 0.3907 & 0.3472 & 0.3931 \\
$0.12-9.8$ & 0.4093 & 0.4257 & 0.3449 & 0.3933 & 0.4305 \\
$0.12-9.9$ & 0.4093 & 0.4257 & 0.3449 & 0.3933 & 0.4304 \\
$0.12-10$ & 0.4093 & 0.4257 & 0.3449 & 0.3933 & 0.4303 \\
$0.14-9.8$ & 0.4093 & 0.4257 & 0.3448 & 0.4222 & 0.4013 \\
$0.14-9.9$ & 0.4093 & 0.4257 & 0.3448 & 0.4222 & 0.4013 \\
$0.14-10$ & 0.4093 & 0.4257 & 0.3448 & 0.4222 & 0.4013 \\
$0.16-9.8$ & 0.4093 & 0.4257 & 0.3448 & 0.4222 & 0.4013 \\
$0.16-9.9$ & 0.4093 & 0.4257 & 0.3448 & 0.4222 & 0.4013 \\
$0.16-10$ & 0.4093 & 0.4257 & 0.3448 & 0.4222 & 0.4013 \\
$0.18-9.8$ & 0.4093 & 0.4465 & 0.4074 & 0.4222 & 0.4013 \\
$0.18-9.9$ & 0.4093 & 0.4464 & 0.4069 & 0.4222 & 0.4013 \\
\hline
\end{tabular}

with different open values, the peak displacement of the pier top of the same pier varies greatly, which indicates that the pier top displacement is more sensitive to the open value. When the open value is greater than $0.14 \mathrm{~m}$, the peak displacement of almost every pier top is relatively stable. That is to say, the peak displacement of pier top turns at the open value of $0.14 \mathrm{~m}$, and no longer drops. This is consistent with the results of the analysis of collision force and number of collisions mentioned above. Therefore, the collision parameters of the collision element are taken as the most disadvantageous values, i.e., the stiffness is $9.9 \times 10^{9}(\mathrm{~N} / \mathrm{m})$ and the open value is $0.14(\mathrm{~m})$.

Figure 7 is the displacemen-time history of the pier top under the most disadvantageous conditions. The analysis shows that the displacement of the pier top changes in the same law, first increases, then decreases, and finally increases. Finally, the reason for the increase is the lag of response caused by inertia, which is the same as the collision force time history mentioned above. Figure 8 shows the longitudinal displacement of the deck, which the change trend is consistent with Figure 7, which shows that the main girder and piers are well connected, and they can well deform together. Under the action of earthquake, the support has not been damaged.

5.3. Analysis of Bearing Parameter. Many bearings are usually used in multispan simply supported beam bridges, and different bearing parameters will seriously affect the collision of bridge structures under earthquakes. Therefore, it is very important to explore the influence of bearing parameters on collision. The optimal collision parameters of the collision element have been determined in Section 2.2 above. In this section, the gap element with the optimal parameters is used to analyze the different bearing stiffness and explore the influence of the support stiffness on the responses of structures. According to Table 1, the first six modes of vibration are mainly longitudinal and vertical vibration, so the effect of the bearing longitudinal stiffness on the impact results is discussed hereon in this study. The bearing stiffness is discretized into points, e.g., $0.8 \times 10^{6} \mathrm{~N} / \mathrm{m}$, $0.9 \times 10^{6} \mathrm{~N} / \mathrm{m}, 1.0 \times 10^{6} \mathrm{~N} / \mathrm{m}, 1.1 \times 10^{6}(\mathrm{~N} / \mathrm{m}), 1.1 \times 10^{6}(\mathrm{~N} / \mathrm{m})$, $1.2 \times 10^{6}(\mathrm{~N} / \mathrm{m}), 1.3 \times 10^{6}(\mathrm{~N} / \mathrm{m}), 1.4 \times 10^{6}(\mathrm{~N} / \mathrm{m})$, and $1.5 \times 10^{6}$ 


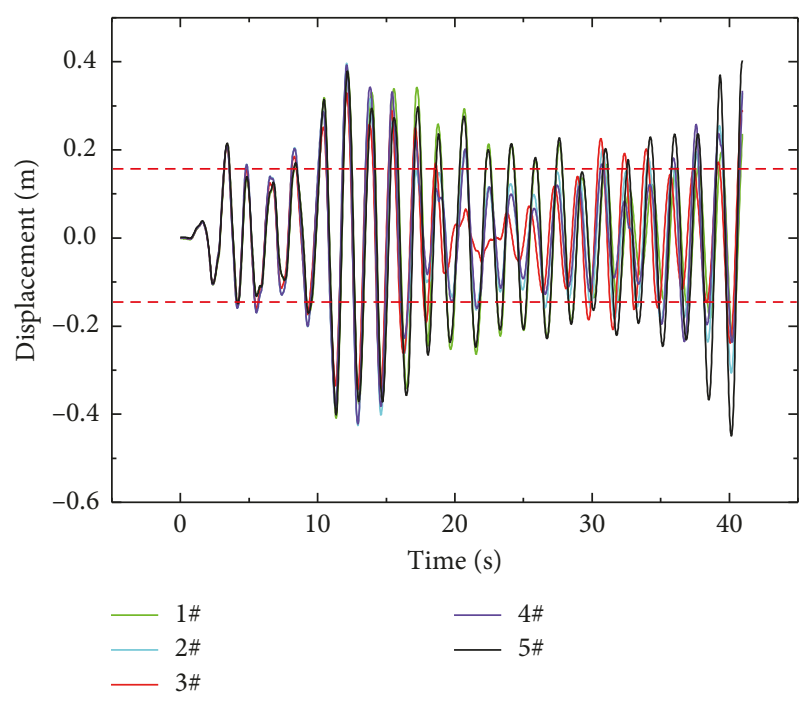

Figure 7: Time history of displacement.

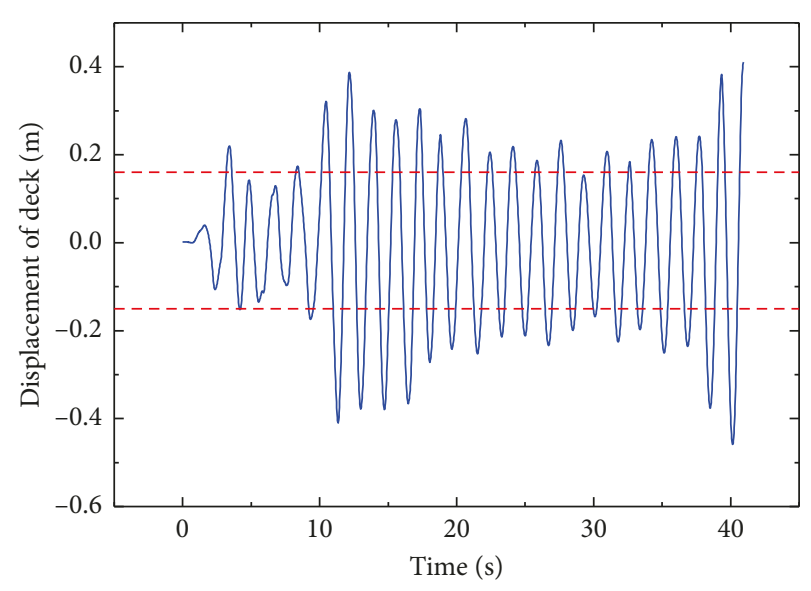

Figure 8: Longitudinal displacement of the deck.

$(\mathrm{N} / \mathrm{m})$, for investigating the influence of bearing stiffness on the collision. The results of this study are also are discussed from the views of collision force and number.

5.3.1. Collision Force and Number. The peak value of collision force and the numbers under the condition of different longitudinal bearing stiffness are shown in Table 3 .

As observed from Table 3, the peak impact force and number of collision experience grow initially, then descend, and eventually ascend with the increase of the longitudinal stiffness of the bearing. For simulating the most disadvantageous situation, further the longitudinal stiffness of the bearing is locked at the value of $1.0 \times 10^{6}(\mathrm{~N} / \mathrm{m})$, because the collision force and the number are the maximum in entire analysis process.

5.3.2. Displacement Response on the Top of Pier 1\# and Deck. The top displacement of pier $1 \#$ and longitudinal displacement of the deck can reflect the degree of collision of simply supported beam bridges from another angle. The varying tendency of displacement response can be
TABLE 3: Collision force and number of collisions.

\begin{tabular}{lcc}
\hline $\begin{array}{l}\text { Longitudinal bearing } \\
\text { stiffness }(\mathrm{N} / \mathrm{m})\end{array}$ & Collision force $(\mathrm{N})$ & Collision number \\
\hline $0.8 \times 10^{6}$ & $8.49 \times 10^{7}$ & 49 \\
$0.9 \times 10^{6}$ & $8.42 \times 10^{7}$ & 47 \\
$1.0 \times 10^{6}$ & $9.62 \times 10^{7}$ & 50 \\
$1.1 \times 10^{6}$ & $8.65 \times 10^{7}$ & 49 \\
$1.2 \times 10^{6}$ & $9.05 \times 10^{7}$ & 43 \\
$1.3 \times 10^{6}$ & $9.21 \times 10^{7}$ & 44 \\
$1.4 \times 10^{6}$ & $9.23 \times 10^{7}$ & 45 \\
$1.5 \times 10^{6}$ & $9.25 \times 10^{7}$ & 47 \\
\hline
\end{tabular}

observed readily in Table 4 and Figures 7 and 8 with different longitudinal stiffness of bearing.

Generally speaking in Table 4, the peak displacement of each pier decreases with the increase of bearing stiffness. This variation depends primarily on two reasons that one is larger stiffness resisting displacement and the other is that the factor is the energy dissipation function of rubber bearing. The bearing is the most vulnerable component in all bridge components under earthquakes. The greater the longitudinal stiffness of bearing, the more restrictive the longitudinal deformation of piers and girders under earthquakes. The range of longitudinal displacement of deck varies from $0.4090 \mathrm{~m}$ to $0.4588(\mathrm{~m})$. The longitudinal displacement of the main girder decreases with the increase of the stiffness of bearing, but there is a sudden change when the stiffness is $1.0 \times 10^{6}(\mathrm{~N} / \mathrm{m})$ and the maximum value is $0.4588(\mathrm{~m})$. It can be concluded that collision is more likely to occur when the stiffness of the support is $1.0 \times 10^{6}(\mathrm{~N} / \mathrm{m})$.

In addition, Table 4 is represented from the aspect of graphic for providing more clearly the changing trend. As seen in Figure 9, the top displacements of 2\# pier and 4\# pier, and $1 \#$ pier and $5 \#$ pier are relatively close, respectively, yet the top displacement of $3 \#$ pier is the smallest, thanks to the structural arrangement symmetrically. Therefore, based on the symmetry of bridge structure, the longitudinal stiffness of the bearing on the side pier may relatively be large in practical engineering. Consequently one can observe more intuitively from Figure 9 that the longitudinal displacement of the main girder has changed abruptly when the stiffness of the bearing is $1.0 \times 10^{6}(\mathrm{~N} / \mathrm{m})$.

5.3.3. Internal Force at the Bottom of Pier. A simply supported beam bridge not only suffers from the damage of main beams but also suffers from the shear failure, bending failure, and bending-shear failure of pier bottom. In order to avoid this kind of damage, it is fairly necessary to check whether the bearing capacity of pier bottom section meets the requirements.

The shearing force and moment at the bottom of piers is listed in Tables 5 and 6, respectively, with different support stiffness. The shearing force and moment decrease implicitly with the increase of the longitudinal stiffness of the bearing. The maximum shearing force at the bottom of piers is $7.935 \times 10^{7}$ (N) occurred at the bottom of piers $1 \#$ and $2 \#$ and the stiffness 
TABle 4: Displacement (m).

\begin{tabular}{|c|c|c|c|c|c|c|}
\hline Bearing stiffness $(\mathrm{N} / \mathrm{m})$ & $1 \#$ & $2 \#$ & $3 \#$ & $4 \#$ & $5 \#$ & Deck \\
\hline $0.8 \times 10^{6}$ & 0.4127 & 0.4274 & 0.3462 & 0.4237 & 0.4029 & 0.4097 \\
\hline $0.9 \times 10^{6}$ & 0.4110 & 0.4273 & 0.3459 & 0.4237 & 0.4029 & 0.4097 \\
\hline $1.0 \times 10^{6}$ & 0.4110 & 0.4273 & 0.3458 & 0.4237 & 0.4028 & 0.4588 \\
\hline $1.1 \times 10^{6}$ & 0.4109 & 0.4272 & 0.3458 & 0.4237 & 0.4028 & 0.4096 \\
\hline $1.2 \times 10^{6}$ & 0.4107 & 0.4271 & 0.3460 & 0.4236 & 0.4027 & 0.4094 \\
\hline $1.3 \times 10^{6}$ & 0.4106 & 0.4270 & 0.3462 & 0.4236 & 0.4026 & 0.4093 \\
\hline $1.4 \times 10^{6}$ & 0.4104 & 0.4269 & 0.3465 & 0.4235 & 0.4024 & 0.4092 \\
\hline $1.5 \times 10^{6}$ & 0.4102 & 0.4268 & 0.3461 & 0.4234 & 0.4023 & 0.4090 \\
\hline
\end{tabular}

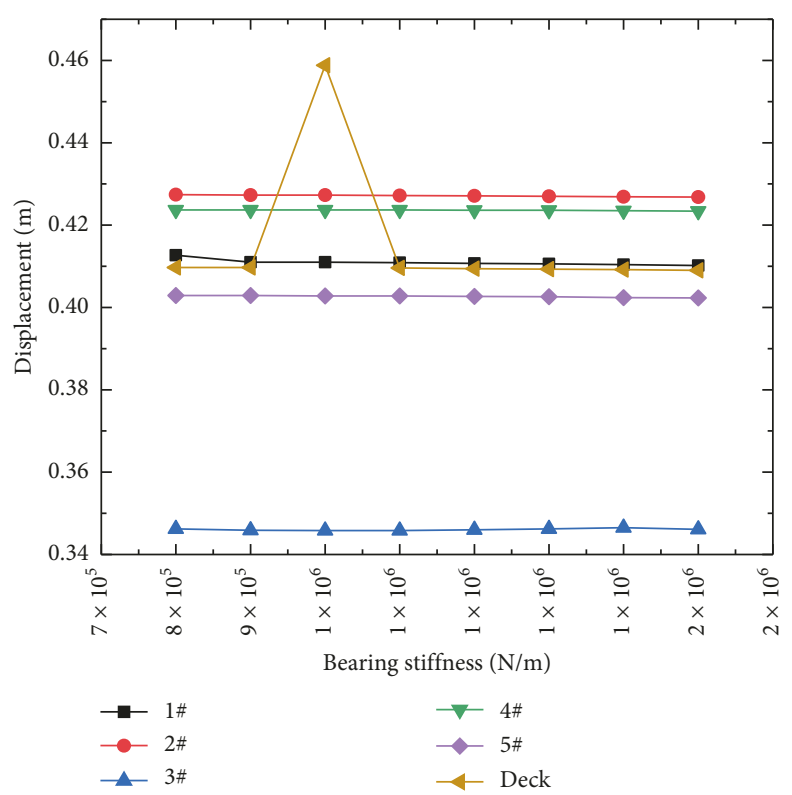

Figure 9: Displacement of top pier and deck.

TABle 5: Shearing force of pier bottom (N).

\begin{tabular}{lccccc}
\hline Bearing stiffness $(\mathrm{N} / \mathrm{m})$ & $1 \#$ & $2 \#$ & $3 \#$ & $4 \#$ & $5 \#$ \\
\hline $0.8 \times 10^{6}$ & $7.276 \times 10^{7}$ & $7.276 \times 10^{7}$ & $6.682 \times 10^{7}$ & $7.924 \times 10^{7}$ & $7.404 \times 10^{7}$ \\
$0.9 \times 10^{6}$ & $7.275 \times 10^{7}$ & $7.275 \times 10^{7}$ & $6.677 \times 10^{7}$ & $7.924 \times 10^{7}$ & $7.404 \times 10^{7}$ \\
$1.0 \times 10^{6}$ & $7.935 \times 10^{7}$ & $7.935 \times 10^{7}$ & $6.674 \times 10^{7}$ & $7.923 \times 10^{7}$ \\
$1.1 \times 10^{6}$ & $7.273 \times 10^{7}$ & $7.273 \times 10^{7}$ & $6.675 \times 10^{7}$ & $7.921 \times 10^{7}$ & $7.403 \times 10^{7}$ \\
$1.2 \times 10^{6}$ & $7.271 \times 10^{7}$ & $7.271 \times 10^{7}$ & $6.677 \times 10^{7}$ & $7.920 \times 10^{7}$ & $7.399 \times 10^{7}$ \\
$1.3 \times 10^{6}$ & $7.268 \times 10^{7}$ & $7.268 \times 10^{7}$ & $6.680 \times 10^{7}$ & $7.919 \times 10^{7}$ & $7.394 \times 10^{7}$ \\
$1.4 \times 10^{6}$ & $7.266 \times 10^{7}$ & $7.266 \times 10^{7}$ & $6.684 \times 10^{7}$ & $7.918 \times 10^{7}$ & $7.392 \times 10^{7}$ \\
$1.5 \times 10^{6}$ & $7.263 \times 10^{7}$ & $7.263 \times 10^{7}$ & $6.690 \times 10^{7}$ & $7.916 \times 10^{7}$ & $7.389 \times 10^{7}$ \\
\hline
\end{tabular}

Table 6: Moment of pier bottom $(\mathrm{N} \cdot \mathrm{m})$.

\begin{tabular}{lccccc}
\hline Bearing stiffness $(\mathrm{N} / \mathrm{m})$ & $1 \#$ & $2 \#$ & $3 \#$ & $4 \#$ & $5 \#$ \\
\hline $0.8 \times 10^{6}$ & $6.93 \times 10^{6}$ & $7.38 \times 10^{8}$ & $6.32 \times 10^{8}$ & $7.45 \times 10^{8}$ & $7.88 \times 10^{8}$ \\
$0.9 \times 10^{6}$ & $7.20 \times 10^{6}$ & $7.38 \times 10^{8}$ & $6.32 \times 10^{8}$ & $7.45 \times 10^{8}$ & $7.43 \times 10^{8}$ \\
$1.0 \times 10^{6}$ & $7.39 \times 10^{6}$ & $7.38 \times 10^{8}$ & $6.32 \times 10^{8}$ & $7.45 \times 10^{8}$ & $7.44 \times 10^{8}$ \\
$1.1 \times 10^{6}$ & $6.92 \times 10^{6}$ & $7.38 \times 10^{8}$ & $6.32 \times 10^{8}$ & $7.02 \times 10^{8}$ \\
$1.2 \times 10^{6}$ & $6.92 \times 10^{6}$ & $7.38 \times 10^{8}$ & $6.41 \times 10^{8}$ & $7.4 \times 10^{8}$ & $7.02 \times 10^{8}$ \\
$1.3 \times 10^{6}$ & $6.91 \times 10^{6}$ & $7.38 \times 10^{8}$ & $6.69 \times 10^{8}$ & $7.02 \times 10^{8}$ \\
$1.4 \times 10^{6}$ & $6.91 \times 10^{6}$ & $7.38 \times 10^{8}$ & $6.34 \times 10^{8}$ & $7.44 \times 10^{8}$ & $7.01 \times 10^{8}$ \\
$1.5 \times 10^{6}$ & $6.91 \times 10^{6}$ & $7.37 \times 10^{8}$ & $7.17 \times 10^{8}$ & $7.44 \times 10^{8}$ & $7.01 \times 10^{8}$ \\
\hline
\end{tabular}


of the bearing is $1.0 \times 10^{6}(\mathrm{~N} / \mathrm{m})$. The moment at the bottom of each pier is also the largest at the stiffness of $1.0 \times 10^{6}(\mathrm{~N} / \mathrm{m})$. It shows that when the stiffness of the bearing is $1.0 \times 10^{6}(\mathrm{~N} / \mathrm{m})$, the internal force at the pier bottom reaches a larger value which considered as the most disadvantageous situation.

\section{Conclusion}

In this study, the nonlinear pounding analysis of a multispan simply supported beam bridge is performed and the following conclusions are drawn:

(1) A three-dimensional finite element model of a multispan simply supported beam bridge is established based on the finite element software of SAP2000. The first two modes of vibration of the considered multispan simply supported beam bridge are mainly longitudinal vibration which may result in the longitudinal pounding.

(2) The selection of collision parameters, e.g., the bearing stiffness, the width of expansion joint, and the impact element stiffness, greatly affect the responses of the multispan simply supported beam bridge subjected to ground motions. The stiffness of $9.9 \times 10^{9}(\mathrm{~N} / \mathrm{m})$ and the open value of $0.14(\mathrm{~m})$ in the impact element can cause most unfavorable responses of structures.

(3) Although the longitudinal stiffness of the bearing has little effect on the impact force and number, it will affect the displacement at the top of piers and the internal force at the bottom of piers to a large extent.

\section{Data Availability}

All the data used to support the findings of this study are included in the paper.

\section{Conflicts of Interest}

The authors declare that they have no conflicts of interest.

\section{Acknowledgments}

The research for this paper was supported by the Science and Technology Plan of Sichuan Science and Technology Department (No. 2019YJ0243), National Science Foundation of China (No. 51308465), and Postdoctoral Science Foundation of China (No. 2015M580031). The authors would like to express their sincere gratitude to all the sponsors for the financial support.

\section{References}

[1] C. J. Lin, H. Hung, Y. Liu, and J. Chai, "Reconnaissance report of 0512 China Wenchuan earthquake on bridges," in Proceedings of the 14th World Conference on Earthquake Engineering, Beijing, China, October 2008.

[2] K. Kawashima, S. Unjoh, J.-I. Hoshikuma, and K. Kosa, "Damage of bridges due to the 2010 Maule, Chile, earthquake," Journal of Earthquake Engineering, vol. 15, no. 7, pp. 1036-1068, 2011.
[3] H.-Y. Jia, X.-L. Lan, S.-X. Zheng, L.-P. Li, and C.-Q. Liu, "Assessment on required separation length between adjacent bridge segments to avoid pounding," Soil Dynamics and Earthquake Engineering, vol. 120, pp. 398-407, 2019.

[4] Q. L. Cheng, Y. Wei, X. Y. Zheng, L. Zheng, and L. Nan, "Base pounding model and response analysis of base-isolated structures under earthquake excitation," Applied Sciences, vol. 7, no. 12, p. 1238, 2017.

[5] H. Naderpour, R. C. Barros, S. M. Khatami, and R. Jankowski, "Numerical study on pounding between two adjacent buildings under earthquake excitation," Shock and Vibration, vol. 2016, Article ID 1504783, 9 pages, 2016.

[6] R. Moghabeli, H. Parastesh, H. Lotfollahian, and M. Parvaresh, "Seismic pounding between adjacent concrete frames," Seismostruct Letters, vol. 1, no. 2, pp. 1-8, 2018.

[7] M. J. N. Priestley, F. Seible, and G. M. Galvi, Seismic Design and Retrofit of Bridges, John Wiley and Sons Inc., Hoboken, NJ, USA, 1996.

[8] C. J. Athanassiadou, G. G. Penelis, and A. J. Kappos, "Seismic response of adjacent buildings with similar or different dynamic characteristics," Earthquake Spectra, vol. 10, no. 2, pp. 293-317, 1994.

[9] R. DesRoches and G. L. Fenves, "New design and analysis procedures for intermediate hinges in multiple frame bridges," Report No. UCB/EERC-97/12, Earthquake Engineering Research Center, University of California, Berkeley, CA, USA, 1997.

[10] P. K. Malhotra, "Dynamics of seismic pounding at expansion joints of concrete bridges," Journal of Engineering Mechanics, vol. 124, no. 7, pp. 794-802, 1998.

[11] R. Jankowski, K. Wilde, and Y. Fujino, "Reduction of pounding effects in elevated bridges during earthquakes," Earthquake Engineering \& Structural Dynamics, vol. 29, no. 2, pp. 195-212, 2000.

[12] S.-H. Kim and M. Shinozuka, "Effects of seismically induced pounding at expansion joints of concrete bridges," Journal of Engineering Mechanics, vol. 129, no. 11, pp. 1225-1234, 2003.

[13] S. A. Anagnostopoulos, "Pounding of buildings in series during earthquakes," Earthquake Engineering \& Structural Dynamics, vol. 16, no. 3, pp. 443-456, 1988.

[14] H. Y. Gou, W. Zhou, G. D. Chen, Y. Bao, and Q. H. Pu, "Insitu test and dynamic analysis of a double-deck tied-arch bridge," Steel and Composite Structures, vol. 27, no. 1, pp. 161-175, 2018.

[15] K. T. Chau, X. X. Wei, X. Guo, and C. Y. Shen, "Experimental and theoretical simulations of seismic poundings between two adjacent structures," Earthquake Engineering \& Structural Dynamics, vol. 32, no. 4, pp. 537-554, 2003.

[16] S. Muthukumar and R. DesRoches, "A Hertz contact model with non-linear damping for pounding simulation," Earthquake Engineering \& Structural Dynamics, vol. 35, no. 7, pp. 811-828, 2006.

[17] P. Zhu, M. Abe, and Y. Fujino, "Modelling three-dimensional non-linear seismic performance of elevated bridges with emphasis on pounding of girders," Earthquake Engineering \& Structural Dynamics, vol. 31, no. 11, pp. 1891-1913, 2002

[18] G. Zanardo, H. Hao, and C. Modena, "Seismic response of multi-span simply supported bridges to a spatially varying earthquake ground motion," Earthquake Engineering \& Structural Dynamics, vol. 31, no. 6, pp. 1325-1345, 2002.

[19] H. Hao, "A parametric study of the required seating length for bridge decks during earthquake," Earthquake Engineering \& Structural Dynamics, vol. 27, no. 1, pp. 91-103, 1998. 
[20] A. Ruangrassamee and K. Kawashima, "Relative displacement response spectra with pounding effect," Earthquake Engineering \& Structural Dynamics, vol. 30, no. 10, pp. 1511-1538, 2001.

[21] R. Jankowski, K. Wilde, and Y. Fujino, "Pounding of superstructure segments in isolated elevated bridge during earthquakes," Earthquake Engineering \& Structural Dynamics, vol. 27, no. 5, pp. 487-502, 1998.

[22] R. Ankowski, K. Wilde, and Y. Fujino, "Reduction of pounding effects in elevated bridges during earthquakes," Earthquake Engineering \& Structural Dynamics, vol. 29, no. 2, pp. 195-212, 2000.

[23] K. Bi, H. Hao, and N. Chouw, "Influence of ground motion spatial variation, site condition and SSI on the required separation distances of bridge structures to avoid seismic pounding," Earthquake Engineering \& Structural Dynamics, vol. 40, no. 9, pp. 1027-1043, 2011.

[24] D.-Y. Zhang, H.-Y. Jia, S.-X. Zheng, W.-C. Xie, and M. D. Pandey, "A highly efficient and accurate stochastic seismic analysis approach for structures under tridirectional nonstationary multiple excitations," Computers \& Structures, vol. 145 , pp. 23-35, 2014.

[25] H.-Y. Jia, D.-Y. Zhang, S.-X. Zheng, W.-C. Xie, and M. D. Pandey, "Local site effects on a high-pier railway bridge under tridirectional spatial excitations: nonstationary stochastic analysis: nonstationary stochastic analysis," Soil Dynamics and Earthquake Engineering, vol. 52, pp. 55-69, 2013.

[26] H. Y. Jia, J. G. Zhao, X. Li, L. P. Li, and S. X. Zheng, "Probabilistic pounding analysis of high-pier continuous rigid frame bridge with actual site condition," Earthquakes and Structures, vol. 15, no. 2, pp. 193-202, 2018.

[27] J.-H. Won, H.-S. Mha II, and S.-H. Kim, "Effects of the earthquake-induced pounding upon pier motions in the multi-span simply supported steel girder bridge," Engineering Structures, vol. 93, pp. 1-12, 2015.

[28] A. Liolios, A. Liolios, G. Hatzigeorgiou, and S. Radev, "Pounding effects on the earthquake response of adjacent reinforced concrete structures strengthened by cable elements," Journal of Theoretical and Applied Mechanics, vol. 44, no. 2, pp. 41-56, 2014.

[29] E. Maragakis, B. Douglas, and S. Vrontinos, "Classical formulation of the impact between bridge deck and abutments during strong earthquake," in Proceedings of the 6th Canadian Conference on Earthquake Engineering, pp. 205-212, University of Toronto Press, Toronto, Canada, June 1991.

[30] R. Jankowski, "Non-linear viscoelastic modelling of earthquake-induced structural pounding," Earthquake Engineering \& Structural Dynamics, vol. 34, no. 6, pp. 595-611, 2005.

[31] T. Hughes, The Finite Element Method-Linear Static and Dynamic Finite Element Analysis, Prentice Hall, Inc., Upper Saddle River, NJ, USA, 1987.

[32] L. Q. Hong, L. Ying, L. Hao, H. G. Hu, and Q. D. Hu, "Seismic response characteristics of stabilizing pile based on elasticplastic analysis," Shock and Vibration, vol. 2018, Article ID 7672587, 15 pages, 2018.

[33] S. A. Anagnostopoulos and K. V. Spiliopoulos, "An investigation of earthquake induced pounding between adjacent buildings," Earthquake Engineering \& Structural Dynamics, vol. 21, no. 4, pp. 289-302, 1992.

[34] J. Azevedo and R. Bento, "Design criteria for buildings subjected to pounding," in Proceedings of the Eleventh World Conference on Earthquake Engineering, Acapulco, Mexico, June 1996.
[35] R. Jankowski, "Non-linear viscoelastic model of structural pounding," in Proceedings of the 13th World Conference on Earthquake Engineering, pp. 1-6, Vancouver, Canada, August 2004.

[36] E. L. Wilson, Three-Dimensional Static and Dynamic Analysis of Structures, Computers and Structures, Inc., Berkeley, CA, USA, 2002.

[37] H. Hao, C. S. Oliveira, and J. Penzien, "Multiple-station ground motion processing and simulation based on SMART1 array data," Nuclear Engineering and Design, vol. 111, no. 3, pp. 293-310, 1989.

[38] D. S. Wang, Q. M. Feng, and G. X. Wang, "Analysis model of pounding between adjacent bridge girders during earthquakes based on collinear compact between rod theory," Engineering Mechanics, vol. 21, no. 2, pp. 157-166, 2004, in Chinese. 


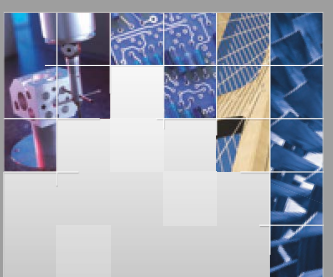

\section{Enfincering}
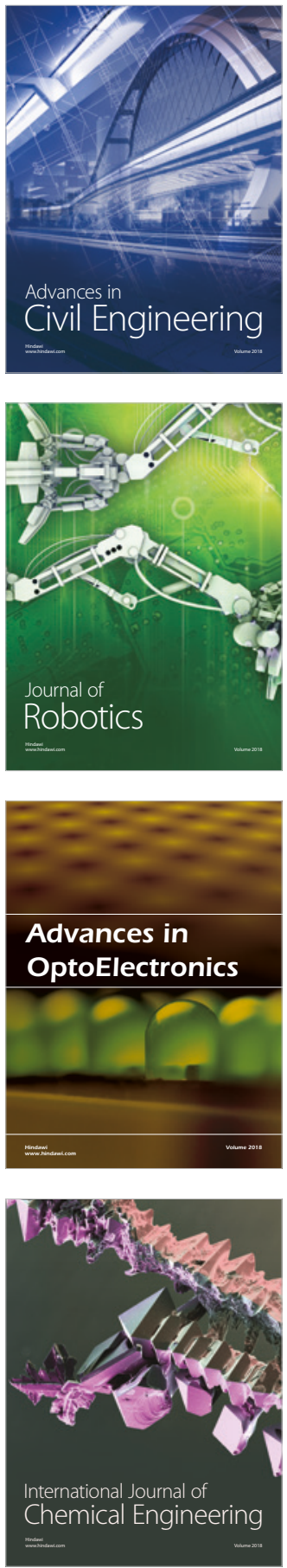

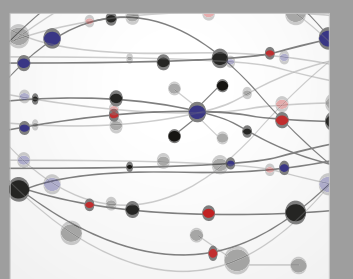

\section{Rotating \\ Machinery}

The Scientific World Journal

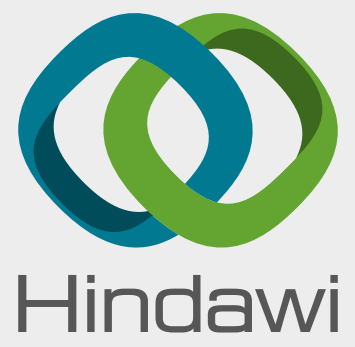

Submit your manuscripts at

www.hindawi.com
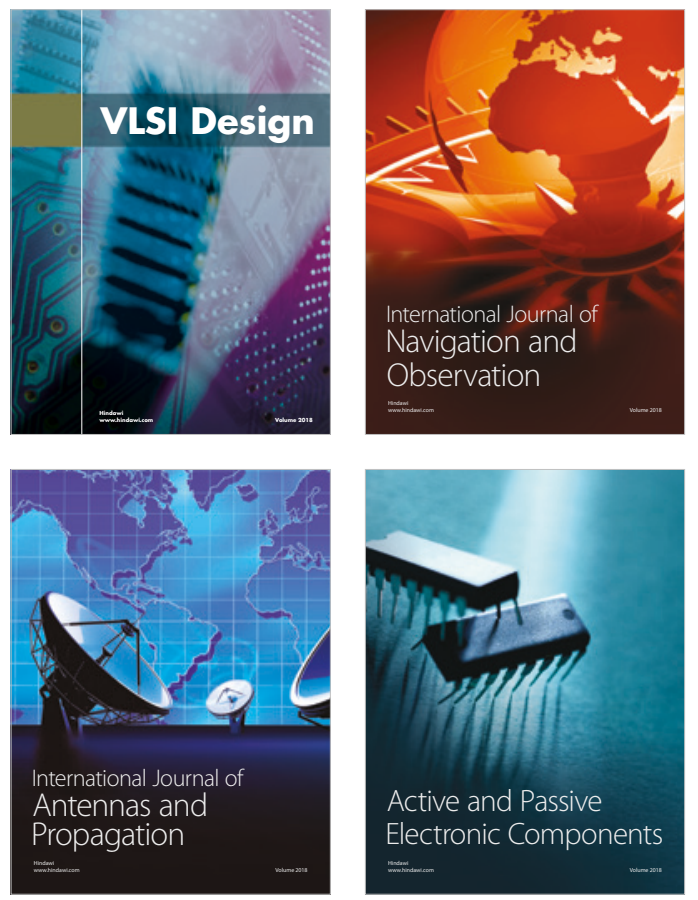
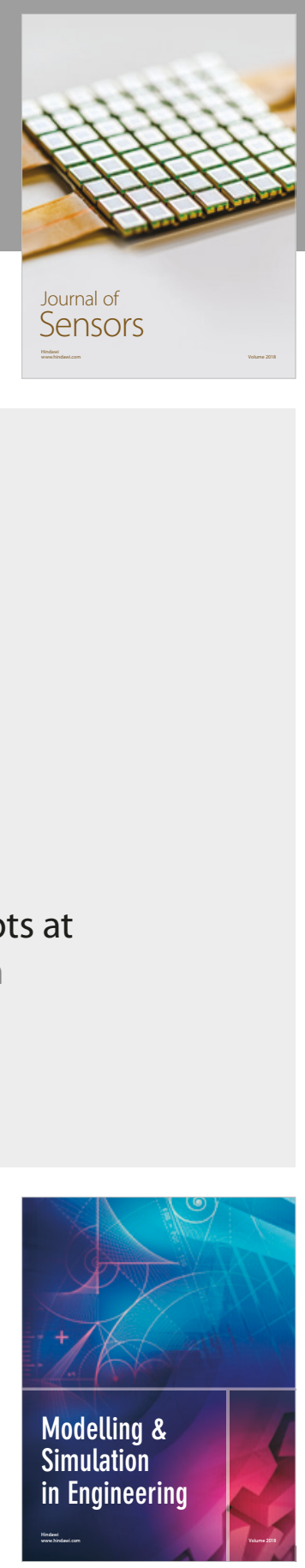

\section{Advances \\ Multimedia}
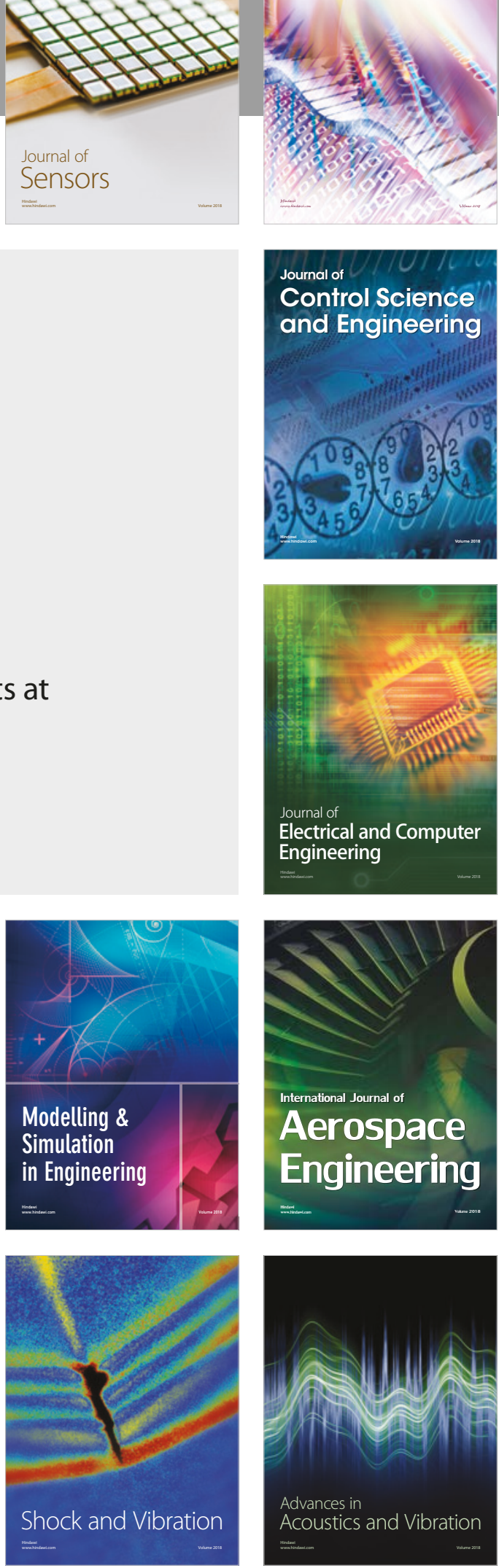